\title{
A New Phytosanitary Method to Reduce the Ascospore Potential of Venturia inaequalis
}

Franziska M. Porsche, Julius Kühn-Institute, Federal Research Center for Cultivated Plants, Institute for Plant Protection in Fruit Crops and Viticulture, 69221 Dossenheim, Germany; Barbara Pfeiffer, State Research Institute for Viticulture \& Pomiculture, 74189 Weinsberg, Germany; and Andreas Kollar, Julius Kühn-Institute, Federal Research Center for Cultivated Plants, Institute for Plant Protection in Fruit Crops and Viticulture

\begin{abstract}
Ascospores of Venturia inaequalis, released from pseudothecia in overwintered, infected apple leaves, serve as the primary inoculum for apple scab. In this study, we tested a new sanitation strategy to reduce ascospore inoculum under orchard conditions over three overwintering periods. After leaf fall, nutrient media containing different concentrations of degraded casein or a yeast extract from Saccharomyces cerivisiae were applied to leaf litter infected with apple scab. The application of 30 and $60 \%$ yeast extract showed the greatest efficacy, and significantly reduced ascospore discharge by $99 \%(P<0.01)$ in 2013 and 2014 . The efficacy of the treatments did not differ from treatment with $5 \%$ urea $(P>0.05)$. Leaf litter decay was

accelerated in the plots treated with yeast extract compared with untreated control plots. Moreover, apple leaves treated with yeast extract had completely decayed due to earthworm activity before ascospore maturity. In comparison, up to $26 \%$ of the leaves in untreated control plots had not decayed. These results suggest that the treatment of leaf litter with yeast extract can almost completely eliminate apple scab inoculum in the course of the whole primary season. These sanitation practices may be beneficial for both organic and conventional cultivation. The reduced infection pressure may allow growers the usage of fungicides with lower efficacy or to reduce the number of applications needed to manage apple scab in spring.
\end{abstract}

Apple scab, caused by Venturia inaequalis (Cooke) G. Winter, is considered to be the most detrimental disease of apple plants worldwide (MacHardy 1996). The disease is spread primarily in temperate zones of the northeastern United States, Canada, Europe, South America, and Asia, where humid, cool, moist weather occurs during the spring months (Biggs and Stensvand 2014; MacHardy 1996). It is less severe in semiarid regions such as western North America, Australia, New Zealand, and South Africa (Biggs and Stensvand 2014; MacHardy 1996).

$V$. inaequalis overwinters as pseudothecia that develop in fallen apple leaves approximately 4 weeks after leaf abscission. Infection is initiated in spring and early summer by ascospores that are released by rainfall from pseudothecia (Alt and Kollar 2010; Bowen et al. 2011; Keitt and Jones 1926; MacHardy et al. 2001; Wallace 1913). Ascospores continue to mature and are discharged over a period of 5 to 9 weeks (Biggs and Stensvand 2014; MacHardy 1996). Infection risk is greatest when leaves and fruit are young and most susceptible (Bowen et al. 2011; Schwabe 1979; Schwabe et al. 1984), and rainy weather conditions with temperatures between 16 and $24^{\circ} \mathrm{C}$ favor scab development (MacHardy, 1996; Mills 1944). In addition, disease incidence depends on cultivar susceptibility and the level of scab resistance, expressed as pits, chlorotic flecks, or necrotic lesions that can contain conidia (MacHardy 1996). The failure to control apple scab results in an extensive reduction in yield and a decrease in the market value of harvested fruit (Carisse and Dewdney 2002). Consequently, high numbers of fungicide applications are required to reduce infections. Apple scab is managed with multisite protectant fungicides such as dithianon, captan, and copper compounds; single-site protectant fungicides such as quinone outside inhibitors; or single-site curative and protective fungicides such as dodine, benzimidazoles, anilinopyrimidines, and demethylation inhibitors (DMI) (Biggs and Stensvand 2014; Carisse and Dewdney 2002; MacHardy

Corresponding author: F. M. Porsche;

E-mail: franziska.porsche@julius-kuehn.de

Accepted for publication 30 October 2016.

This article is in the public domain and not copyrightable. It may be freely reprinted with customary crediting of the source. The American Phytopathological Society, 2017.
1996). However, V. inaequalis has become less sensitive to all single-site protectant and curative fungicides over the past decades (Carisse and Dewdney 2002; Chapman et al. 2011). Furthermore, the high cost of fungicides and potential harm to the environment have generated increasing interest in the development of alternative strategies for the management of apple scab in order to reduce reliance on fungicides.

Orchard sanitation practices can significantly reduce the amount of ascosporic inoculum and, therefore, increase the efficacy of fungicide applications (Biggs and Stensvand 2014). In the past, many attempts were made to prevent the formation of pseudothecia. Studies investigated the effect of application of various chemicals (e.g., copper-lime-arsenite, ammonium sulfate, phenylmercuric chloride, and sodium dinitro-o-cresolate) and fungicides (e.g., benzimidazoles, DMI, dodine, and captan) to fallen leaves in the orchard in their ability to eradicate the pseudothecia of $V$. inaequalis (MacHardy 1996). Most of these compounds were found to completely eliminate ascospore inoculum. However, due to environmental concerns such as health concerns for farmers and consumers, adverse effects on ground fauna and microorganisms, and entry in the ground water, none of these compounds have been incorporated into leaf litter management programs for apple scab.

Physical control strategies have included the removal of fallen leaves by burning (Keitt 1936), shredding, and mulching (Sutton et al. 2000; Sutton and MacHardy 1993; Vincent et al. 2004); vacuum cleaning techniques (Benduhn et al. 2014); or covering the ground of the orchard with plastic (Holb et al. 2004). These strategies were found to be suitable for the reduction of $V$. inaequalis ascospore inoculum but may not be practical, except for their use in small orchards.

The application of $5 \%$ urea after harvest but before the shedding of leaves is the standard phytosanitary method in integrated orchards to reduce overwintering inoculum (Biggs and Stensvand 2014; MacHardy 1996; Sutton et al. 2000). The application of urea significantly accelerates the rate of leaf decomposition (Biggs and Stensvand 2014) due to the quantitative shift in microbial populations (Burchill et al. 1965; Crosse et al. 1968). In addition, urea contributes to the softening of leaf litter, which increases the activity of earthworms (Helling and Larink 1998; Lowe and Butt 2003; Satchell 1967; Satchell and Loewe 1967; Wright 1972). However, urea is not an organically approved material in many fruit-growing areas. 
There is an urgent need for effective sanitation methods in applegrowing areas which are both economically reasonable and easy to perform. Rüdiger et al. (2012) found that treatment of leaf litter with nutrient solutions can reduce ascospore inoculum in the orchard by more than $90 \%$. The purpose of this study was to (i) develop effective leaf litter treatments using nutrient media in order to suppress pseudothecial development or (ii) limit the ascospore discharge of $V$. inaequalis, and (iii) compare the efficacy of these treatments with urea. The ascospore potential was used to determine the efficacy of media with different nutrient composition, in addition to the optimal frequency and timing of leaf litter application. We hypothesized that the nutrient media would enhance the burrowing activity of earthworms and, therefore, result in the complete removal of leaf litter before bud break. These phytosanitary measures could be used in practice if they show the potential to eliminate the ascospore potential of $V$. inaequalis. This would be of particular benefit for organic fruit farming, and may allow growers to use fungicides with lower efficacy or to reduce the number of applications needed to manage apple scab in early spring.

\section{Materials and Methods}

Preparation of nutrient solutions. Urea (AppliChem $\mathrm{GmbH}$, Darmstadt, Germany), casamino acids (Sigma-Aldrich Chemie GmbH, Steinheim, Germany), yeast extract (YE06; Bouillon N, LS; Leiber $\mathrm{GmbH}$, Bramsche, Germany), tryptic soy broth (Sigma-Aldrich Chemie $\mathrm{GmbH}$ ), peptone casein (Sigma-Aldrich Chemie $\mathrm{GmbH}$ ), and amino acids (Carl Roth GmbH \& Co KG, Karlsruhe, Germany) were dissolved in ultrapure water at the concentrations described in Tables 1 and 2, then frozen $\left(-20^{\circ} \mathrm{C}\right)$ until use.

The 15, 30, and 60\% yeast extracts (YE15, YE30, and YE60) were prepared using an autolysis product from Saccharomyces cerivisiae (Leiber yeast extract $\mathrm{S}$; Leiber $\mathrm{GmbH}$ ) originating from the brewery industry. YE60 was prepared with $600 \mathrm{~g}$ of yeast extract dissolved in $1,000 \mathrm{ml}$ of ultrapure water. The suspension was centrifuged for $30 \mathrm{~min}$ at 10,000 rpm (Beckman JA-14; Beckman Coulter, Brea, $\mathrm{CA})$ at $21^{\circ} \mathrm{C}$. The supernatant was removed, after which the pellet was resuspended in $1,000 \mathrm{ml}$ of ultrapure water and centrifuged again. The combined supernatants made up the YE60 solution, and a 1:4 dilution was used for the YE15 solution. The YE30 solution was prepared following the same procedure but using $300 \mathrm{~g}$ of yeast extract.

Leaf litter treatments and potential ascospore release. At the beginning of leaf fall on 27 October 2011, 5 November 2012, and 12 November 2013, naturally infected apple leaves from trees of different cultivars were collected from commercial orchards in Germany (Würzburg and Heilbronn). The experimental studies were conducted in the Heuchlingen orchard $\left(49^{\circ} 15^{\prime} 02^{\prime \prime} \mathrm{N} ; 9^{\circ} 13^{\prime} 34^{\prime \prime} \mathrm{E}\right)$ at the State Research Institute for Viticulture \& Pomiculture (LVWO) in Weinsberg and the Julius Kühn-Institute (JKI) in Dossenheim $\left(49^{\circ} 26^{\prime} 54.43^{\prime \prime} \mathrm{N} ; 8^{\circ} 38^{\prime} 30.79^{\prime \prime} \mathrm{E}\right)$. The leaves were air dried for several days under natural conditions, while sheltered from rain. The airdried leaves were placed in plastic trays ( 55 by 30 by $7 \mathrm{~cm} ; 80 \mathrm{~g}$ dry weight $[\mathrm{DW}]$ of leaves), covered with a wire mesh, and placed in the orchards. Each tray was perforated with six holes $(3 \mathrm{~mm}$ in diameter) so that the rainwater could drain onto the ground. The trays were regularly monitored to remove any leaf debris clogging the holes. The experiments were conducted using a completely randomized design with three plots of residuals per treatment.

Earthworm experiments were set up at the LVWO, where selected leaves were evenly distributed on the soil, while being protected by a wooden frame fixed with wire mesh $(85$ by $59 \mathrm{~cm}, 170 \mathrm{~g} \mathrm{DW}$ of leaves). A randomized complete block design with three replicates per treatment was used in all 3 years $(2011,2012$, and 2013).

The leaf litter in each plastic tray was treated with the nutrient solution between one and four times in late autumn and winter. Precise application dates and treatments are given in Table 1. The leaf litter used for the earthworm experiments was treated between two and four times (Table 2). Untreated leaf litter served as a control. All nutrient solutions were sprayed on top of the leaves until runoff began (approximately $100 \mathrm{ml}$ ). The first treatments were performed after approximately $90 \%$ of the annual leaf fall had occurred (21 November 2011, 21 November 2012, and 9 December 2013).

During the period of ascospore release, leaf samples from each of the treated and untreated leaf litter experiments were sampled weekly and dried overnight in the laboratory. The ascospore discharge was determined from $1 \mathrm{~g} \mathrm{DW}$ of leaf material, according to the water bath method (Kollar 1998). Ascospore counts were performed twice for each sample using a Kolkwitz plankton cytometer $(0.5 \mathrm{ml}$; Hydro-Bios, Kiel, Germany). The cumulative ascospore potential of the leaf litter samples was calculated as the sum of the mean weekly ascospore counts over the course of the primary scab season per year (end of March until the end of May). The level of efficiency $(\% \mathrm{E})$ of each treatment on the leaf litter ascospore potential, compared with the untreated control, was calculated using the following formula: $\% \mathrm{E}=(\Sigma \mathrm{wAct} \times 100) / \Sigma \mathrm{wAcc}$, where $\Sigma \mathrm{wAcc}$ is the sum of the mean weekly ascospore counts in the control plots and $\Sigma$ wAct is the sum of the mean weekly ascospore counts in the treated plots.

The $\mathrm{pH}$ values of each of the ascospore suspensions and nutrient media were recorded at ambient temperature using a glass electrode (766 Calimatic pH meter; Knick, Berlin). Leaf decay in the plastic trays was assessed twice a month and documented with a digital camera.

Feeding activity of earthworms was monitored and documented during the whole time of the experiments with a time-lapse camera (Brinno Garden Watch Cam, GWCTLC130A; Palm City, FL). In

Table 1. Nutrient solutions, concentrations (Conc.), and frequencies used in this study for the treatment of leaf litter infected with Venturia inaequalis in plastic trays

\begin{tabular}{|c|c|c|c|c|c|c|}
\hline \multirow[b]{2}{*}{ Media } & \multirow[b]{2}{*}{ Conc. (\%) } & \multicolumn{4}{|c|}{$\begin{array}{l}\text { Application } \\
\text { schedule }^{\mathbf{a}}\end{array}$} & \multirow[b]{2}{*}{ Abbreviation } \\
\hline & & 1 & 2 & 3 & 4 & \\
\hline \multicolumn{7}{|l|}{ 2011-12 } \\
\hline Control & $\ldots$ & - & - & - & - & $\mathrm{C}$ \\
\hline Urea & 5 & + & + & + & + & $\mathrm{U}$ \\
\hline Casamino acids & 6 & + & + & + & + & $\mathrm{CA}$ \\
\hline Yeast extract & 6 & + & + & + & + & YE06 \\
\hline Peptone casein & 6 & + & + & + & + & $\mathrm{PC}$ \\
\hline Amino acids & Various $^{\mathrm{b}}$ & + & + & + & + & $\mathrm{AA}$ \\
\hline Tryptic soy broth & 9 & + & + & + & + & TSB \\
\hline \multicolumn{7}{|l|}{$2012-13$} \\
\hline Control & $\ldots$ & - & - & - & - & $\mathrm{C}$ \\
\hline Urea & 5 & + & + & + & + & $\mathrm{U}$ \\
\hline Casamino acids & 6 & + & + & + & + & $\mathrm{CA}$ \\
\hline Yeast extract & 6 & + & + & + & + & YE06 \\
\hline Yeast extract & 60 & + & + & + & + & YE60 \\
\hline Yeast extract & 15 & + & + & + & + & YE15 \\
\hline \multicolumn{7}{|l|}{ 2013-14 } \\
\hline Control & $\ldots$ & - & - & - & - & $\mathrm{C}$ \\
\hline Urea & 5 & + & + & + & + & $\mathrm{U}$ \\
\hline Yeast extract & 60 & + & + & + & + & YE60a \\
\hline Yeast extract & 60 & + & + & - & - & YE60b \\
\hline Yeast extract & 60 & - & - & + & + & YE60c \\
\hline Yeast extract & 60 & - & + & - & - & YE60d \\
\hline Yeast extract & 30 & + & + & + & + & YE30a \\
\hline Yeast extract & 30 & + & + & - & - & YE30b \\
\hline Yeast extract & 30 & - & - & + & + & YE30c \\
\hline Yeast extract & 30 & - & + & - & - & YE30d \\
\hline
\end{tabular}

a Application dates for 2011-12 were 21 November 2011, 19 December 2011, 16 January 2012, and 16 February 2012; dates for 2012-13 were 21 November 2012, 19 December 2012, 15 January 2013, and 13 February 2013; and dates for 2013-14 were 9 December 2013, 7 January 2014, 28 January 2014, and 24 February 2014; - = no application and $+=$ application.

${ }^{b}$ Amino acid concentrations consisted of $2.8 \%$ isoleucine, $4.6 \%$ leucine, $3.5 \%$ lysine, $11.3 \%$ methionine, $0.3 \%$ cysteine, $2.2 \%$ phenylalanine, $2.2 \%$ tyrosine, $2.0 \%$ threonine, $6.4 \%$ tryptophan, $1.2 \%$ histidine, $1.6 \%$ alanine, $3.6 \%$ aspartic acid, $9.9 \%$ glutamic acid, $1.0 \%$ glycine, $4.6 \%$ proline, $2.5 \%$ serine, $3.0 \%$ valine, and $1.6 \%$ arginine. 
addition, images of each tray were taken with a digital camera every 2 weeks. Leaf litter decay and removal was estimated by laying a grid (four by four squares) above the images and comparing initial leaf litter amount at the beginning of the experiment with the remaining leaf litter material (percent).

Table 2. Nutrient solutions, concentrations (Conc.), and frequencies for leaf litter treatments on the soil tested in their ability to increase the decomposition of leaf litter due to earthworm activity

\begin{tabular}{|c|c|c|c|c|c|c|}
\hline \multirow[b]{2}{*}{ Media } & \multirow[b]{2}{*}{ Conc. $(\%)$} & \multicolumn{4}{|c|}{$\begin{array}{l}\text { Application } \\
\text { schedule }^{\mathrm{a}}\end{array}$} & \multirow[b]{2}{*}{ Abbreviation } \\
\hline & & 1 & 2 & 3 & 4 & \\
\hline \multicolumn{7}{|l|}{ 2011-12 } \\
\hline Control & $\ldots$ & - & - & - & - & $\mathrm{C}$ \\
\hline Casamino acids & 6 & + & + & + & + & $\mathrm{CA}$ \\
\hline Yeast extract & 6 & + & + & + & + & YE06 \\
\hline Peptone casein & 6 & + & + & + & + & $\mathrm{PC}$ \\
\hline Tryptic soy broth & 9 & + & + & + & + & TSB \\
\hline \multicolumn{7}{|l|}{$2012-13$} \\
\hline Control & $\ldots$ & - & - & - & - & $\mathrm{C}$ \\
\hline Casamino acids & 6 & + & + & + & - & $\mathrm{CA}$ \\
\hline Yeast extract & 6 & + & + & + & - & YE06 \\
\hline Yeast extract & 60 & + & + & + & - & YE60 \\
\hline \multicolumn{7}{|l|}{$2013-14$} \\
\hline Control & $\ldots$ & - & - & - & - & $\mathrm{C}$ \\
\hline Yeast extract & 30 & + & + & - & - & YE30 \\
\hline Yeast extract & 6 & + & + & - & - & YE06a \\
\hline Yeast extract & 6 & - & + & + & - & YE06b \\
\hline $\begin{array}{l}\text { a Application dates f } \\
\text { March 2012, and } \\
\text { 2012, } 8 \text { January } 20 \\
\text { 4 December 2013, } \\
\text { and + = applicatior }\end{array}$ & $\begin{array}{l}\text { 11-12 were } \\
\text { March 2012; } \\
\text { and } 13 \text { Febr } \\
\text { luary } 2014 \text {, }\end{array}$ & & vem & 20 & 1,1 & $\begin{array}{l}\text { January } 2012,5 \\
23 \text { November } \\
2013-14 \text { were } \\
=\text { no application }\end{array}$ \\
\hline
\end{tabular}

Data analysis. Data collected from the weekly ascospore counts between 2012 and 2014 were analyzed separately for each year. Mean comparisons across treatment groups were conducted using one-tailed Mann-Whitney U tests. Statistical analyses of all data were performed with Microsoft Excel software (version 2007; Microsoft Corp., Redmond, WA) and the Mann-Whitney U test add-on for Excel (J. H. McDonald, University of Delaware, Newark). A $P$ value $<0.05$ was considered to indicate significant differences in the ascospore counts.

The experimental data collected from each plot of the earthworm activity experiments were combined and submitted to analyses of variance (Levene's test) according to randomized block design. The means were separated by an unpaired one-sided $t$ test (Microsoft Excel, version 2007). Significance was assessed at $P<0.05$.

\section{Results}

Ascospore potential in leaf litter treated with yeast extracts and degraded casein media. Ascospore maturation was associated with bud break and leaf unfurling in all years investigated. The first of the matured ascospores were found between the end of March and the beginning of April. From 2012 to 2014, the pattern of ascospore discharge over time was similar for the treated and untreated leaves, with maximum amounts of ascospores measured on 8 May 2012, 29 April 2013, and 16 April 2014 (Fig. 1). In total, $0.45 \pm 0.2$ million ascospores/g DW was quantified in the untreated leaf litter between 10 April and 12 June 2012, $1.4 \pm 0.5$ million ascospores/g DW was quantified between 15 April and 27 May 2013, and $1.3 \pm 0.6$ million ascospores/g DW between 20 March and 8 May 2014.

The total numbers of ascospores quantified in the untreated leaf litter trays in the primary apple scab seasons 2012, 2013, and 2014 were comparable, and did not differ within the same year of investigation. Treatment with 5\% urea reduced ascospore discharge significantly by $97 \%(P<0.001)$ in $2012,100 \%(P=0.01)$ in 2013 , and $99 \%$ $(P=0.002)$ in 2013 compared with the untreated control (Fig. 2).
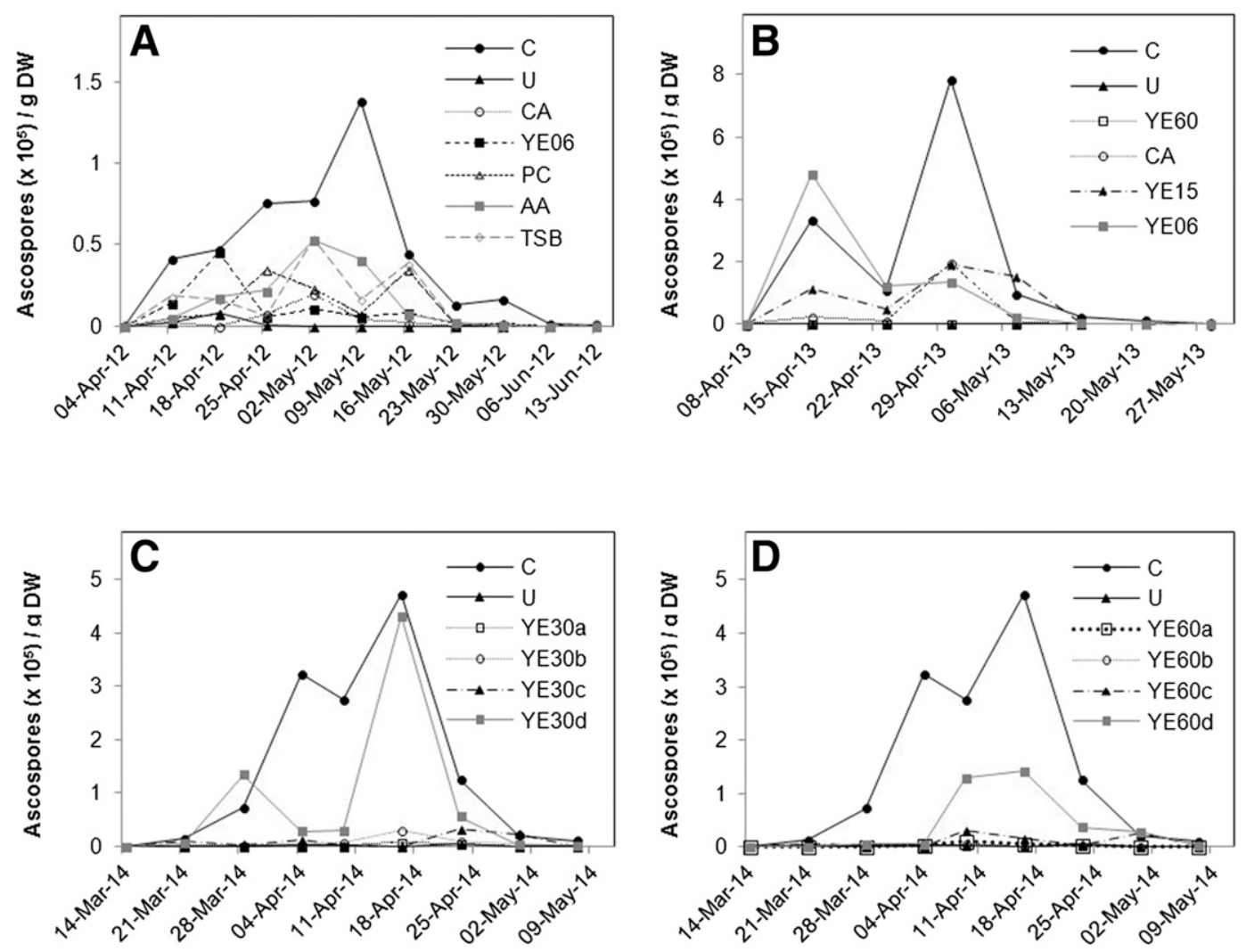

Fig. 1. Weekly ascospore numbers per milliliter in untreated leaf litter (C) and leaf litter treated with urea (U), casamino acids (CA), yeast extract $60 \%$ (YE60), yeast extract 30\% (YE30), yeast extract 15\% (YE15), and yeast extract 6\% (YE06) in the orchard at the Julius Kühn-Institute (Dossenheim) in A, 2012; B, 2013; and C and D, 2014. Ascospore release was determined weekly during the ascospore release period from $1 \mathrm{~g}$ of dry weight leaf tissue collected from each depot. Ascospore counts were performed twice per sample. 
Application of the casein media tryptic soy broth, amino acids and peptone casein reduced the ascospore potential by $62 \%, 64 \%$ and $71 \%$ in 2012 . The greatest ascospore reduction was observed in the leaf litter treated with casamino acids, where ascospore production was reduced significantly by $81 \%(P<0.01)$ in 2012 and $91 \%$ $(P<0.04)$ in 2013 . The efficacy of the yeast extract was associated with the concentration applied. The leaf litter which was treated with $6 \%$ yeast extract had significantly reduced ascospore inoculum by $78 \%$ $(P<0.01)$ in 2012 . However, in 2013 , the $6 \%$ yeast extract treatment did not significantly reduce ascospores $(39 \% ; P>0.05)$. Application of yeast extract at the higher $60 \%$ concentration almost completely inhibited ascospore development in 2013 and 2014. The frequency of application had a strong effect on the efficacy of the yeast extracts. In 2014, four applications of the 30 and $60 \%$ yeast extract reduced ascospore development by 98 to $99 \%$. Two applications of both media concentrations inhibited ascospore production by 93 to $99 \%$, and the treatments applied soon after leaf fall tended to further improve the efficacy compared with the treatments in late winter. A single treatment of the leaf litter with $60 \%$ yeast extract was found to be less efficient, with a $74 \%$ reduction in ascospore inoculum compared with the control. A single treatment with the $30 \%$ yeast extract reduced the ascospore discharge by $46 \%$. The ascospore potentials determined at the LVWO (data not shown) and JKI orchards were indistinguishable $(P>0.05)$ for all seasons according to Mann-Whitney U test.

The measured $\mathrm{pH}$ values from the nutrient solutions applied to apple leaf litter were 5.0 to 7.3 in 2011, 2012, and 2013. The $\mathrm{pH}$ of the ascospore suspensions from all leaf litter depots ranged from 5.6 to 7.4.

Enhanced leaf litter decay was associated with increased earthworm activity. The application of the nutrient solutions accelerated leaf litter decay in the plots protected from earthworms. The first signs of decomposition were detected at the end of January until the end of February in every year of the study. When compared with the untreated control leaves, the treated leaves had structural changes indicating decay, including small lesions and detachment of the epidermal layer (Fig. 3). Leaf decay progressed continuously until ascospore maturation. A particularly intense decomposition of leaves treated with peptone casein and casamino acids was observed in 2012. Slight indications of accelerated leaf decay were visible in the leaf litter treated with 5\% urea, $6 \%$ yeast extract, tryptic soy broth, or amino acids. The most intense leaf decay was observed for leaf litter treated with 60\% yeast extract in 2013 and 2014 (Fig. 3). Furthermore, the application of four treatments showed the most extensive decay, and a single treatment only was associated with the least decay.

Feeding activity of earthworms was observed with the time-lapse camera primarily in the dark. Images revealed that earthworms pulled the leaves into their burrows. Other insects or detritivores were not involved in leaf litter removal. In the Heuchlingen orchard, the leaf litter density in all plots decreased from the first leaf litter treatment until ascospore maturation (Fig. 4). Leave litter removal and decay by earthworm activity was higher in litter collections treated with nutrient solution and yeast extract compared with the untreated control. At the beginning of ascospore season (10 April 2012), 35\% of the initial leaves in the earthworm assays remained in the untreated plots. Only 8 to $13 \%$ of the initial leaf material remained in the leaf litter treated with casamino acids and peptone casein, $12 \%$ for the leaf litter treated with tryptic soy broth, and $18 \%$ treated with the $6 \%$ yeast extract. However, there were no significant reductions in leaf litter material according to the unpaired one-sided $t$ test $(P>0.05)$, except for the leaf litter treated with casamino acids $(P=0.03)$. At the beginning of January 2013, enhanced leaf litter removal was observed as a result of application of $6 \%$ yeast extract and casamino acids. This increased leaf litter decay resulted in $25 \%$ of leaf litter remaining $(P=0.02)$ and, with $60 \%$ yeast extract, $10 \%$ of leaf litter remaining $(P=0.01)$, compared with $70 \%$ in the control. At the beginning of ascospore maturation (27 March 2013), 15\% of the initial leaf material remained in the untreated control trays. Application of $60 \%$ yeast extract and casamino acids to the leaf litter resulted in the complete removal of all leaf blades; only the petioles remained. In 2014, the leaves treated with two applications of 6 or $30 \%$ yeast extracts soon after leaf fall were completely removed by earthworm activity before ascospore maturation. Two treatments with the $6 \%$ yeast extract in late winter were less efficient. Approximately $10 \%$ of the initial leaf material remained compared with $26 \%$ of leaf litter in the untreated tray.

\section{Discussion}

The present study demonstrated that treating leaf litter with nutrient media resulted in a significant reduction in ascospore discharge
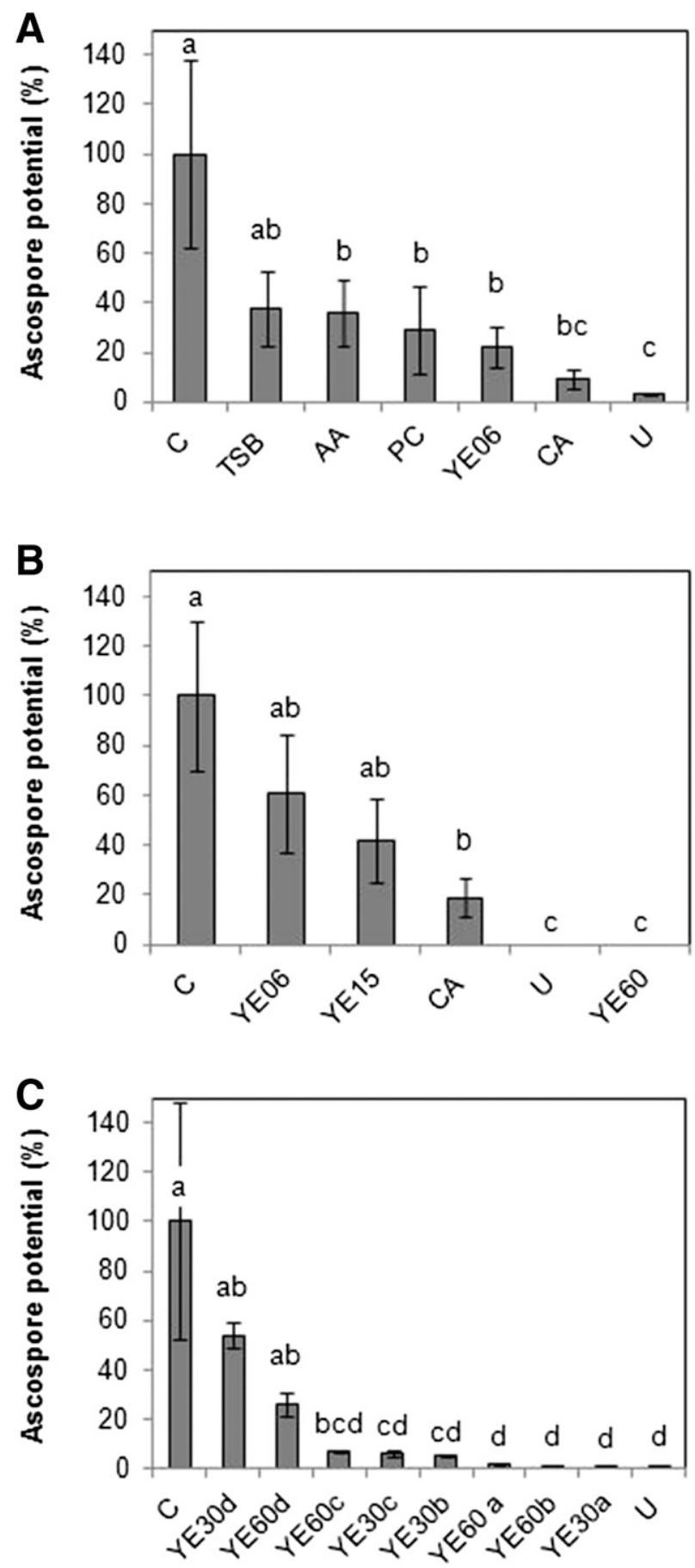

Fig. 2. Cumulative ascospore potential in trays containing leaf litter treated with tryptic soy broth (TSB), amino acids (AA), peptone casein (PC), urea (U), casamino acids (CA), yeast extract $60 \%$ (YE60), yeast extract $30 \%$ (YE30), yeast extract $15 \%$ (YE15), and yeast extract 6\% (YE06) versus untreated control (C) leaf litter, in the orchard at the Julius Kühn-Institute (Dossenheim) in A, 2012; B, 2013; and C, 2014. The untreated control sample contained a total of 0.45 million ascospores $/ g$ dry weight (DW) in 2012, 1.4 million ascospores/g DW in 2013, and 1.3 million ascospores/g DW in 2014, which was defined as $100 \%$ and used as the reference. The ascospore potential in the treated leaf litter depots is shown in comparison. Bars with the same letters are not significantly different according to the MannWhitney $U$ test $(P>0.05)$. Error bars presented are the standard error of the mean. 
the following spring, thereby impairing the lifecycle of $V$. inaequalis. Leaf litter treatments performed in late autumn and winter with degraded casein (enzymatic digests or acid hydrolysis) significantly reduced ascospore discharge from 62 to $91 \%$. Our findings are similar to those obtained by Rüdiger et al. (2012), who observed a greater than $90 \%$ reduction in ascospore potential in apple leaf litter treated with degraded casein media after leaf fall and incubated in an orchard.

Applications of 30 and $60 \%$ yeast extract completely eradicated ascospore production in 2013 and 2014 (Fig. 2). The efficacy of the yeast extract was related to the applied concentration and number of leaf litter treatments. Between two and four applications of the 30 or $60 \%$ yeast extract achieved sufficient impairment of pseudothecial development. In contrast, a single application did not reduce the ascospore discharge, probably due to lower leaf decomposition observed in the plots. A second treatment approximately 4 to 6 weeks after the first application appeared to be sufficient to completely eradicate the ascospore inoculum. Lower yeast extract concentrations of 6 and $15 \%$ failed to significantly reduce ascospore discharge.

The timing of applications had an influence on the efficacy of the yeast extract. Treatments of the leaf litter when $90 \%$ of leaves had been shed from the trees had a greater effect on ascospore reduction (95 to 99\%) compared with treatments that were applied in late winter (93 to 94\%) (Table 1; Fig. 4). The decreased ascospore inoculum appeared to be due to failure of the fungus to produce vital pseudothecia in the period following leaf fall until spring. This suggests that the inhibition may occur at an early stage of pseudothecia initiation or development. The results are similar to those obtained by Burchill (1968). The author proved that urea treatments in autumn were more effective when applied in October compared with November.

The effect of the yeast extract treatments was not caused by a shift in $\mathrm{pH}$ on leaf litter surface. The influence of $\mathrm{pH}$ on pseudothecial development has been investigated in several studies (Cook 1969; MacHardy 1996; Ross and Hamlin 1962). Alkaline or acidic media were applied to detached scabbed leaves at weekly intervals, and pseudothecial production was found to be prevented when the mean $\mathrm{pH}$ on the surface of the leaf was $\leq 4$ or $\geq 7.5$. In the current study, the $\mathrm{pH}$ of the ascospore suspensions from the treated plots ranged from 5.6 to 7.4. Therefore, a direct effect of the yeast extract on pseudothecial development due to changes in the $\mathrm{pH}$ value can be excluded.

Application of 5\% urea postharvest, before leaf fall, is the standard phytosanitary method in integrated fruit production used to suppress pseudothecial formation on overwintered apple leaf litter (Carisse and Dewdney 2002). In this study, application of urea resulted in consistently high ascospore inhibition, varying from 97 to $100 \%$, in the apple scab seasons between 2012 and 2014 (Fig. 2). These results are in agreement with those obtained by Burchill et al. (1965), who showed that treatment with $5 \%$ urea on detached leaves in autumn reduced ascospore production by $97 \%$. The leaves were overwintered under controlled conditions, and noticeably enhanced leaf decomposition occurred until the beginning of ascospore maturation. Similar effects were observed in this study with the $5 \%$ urea

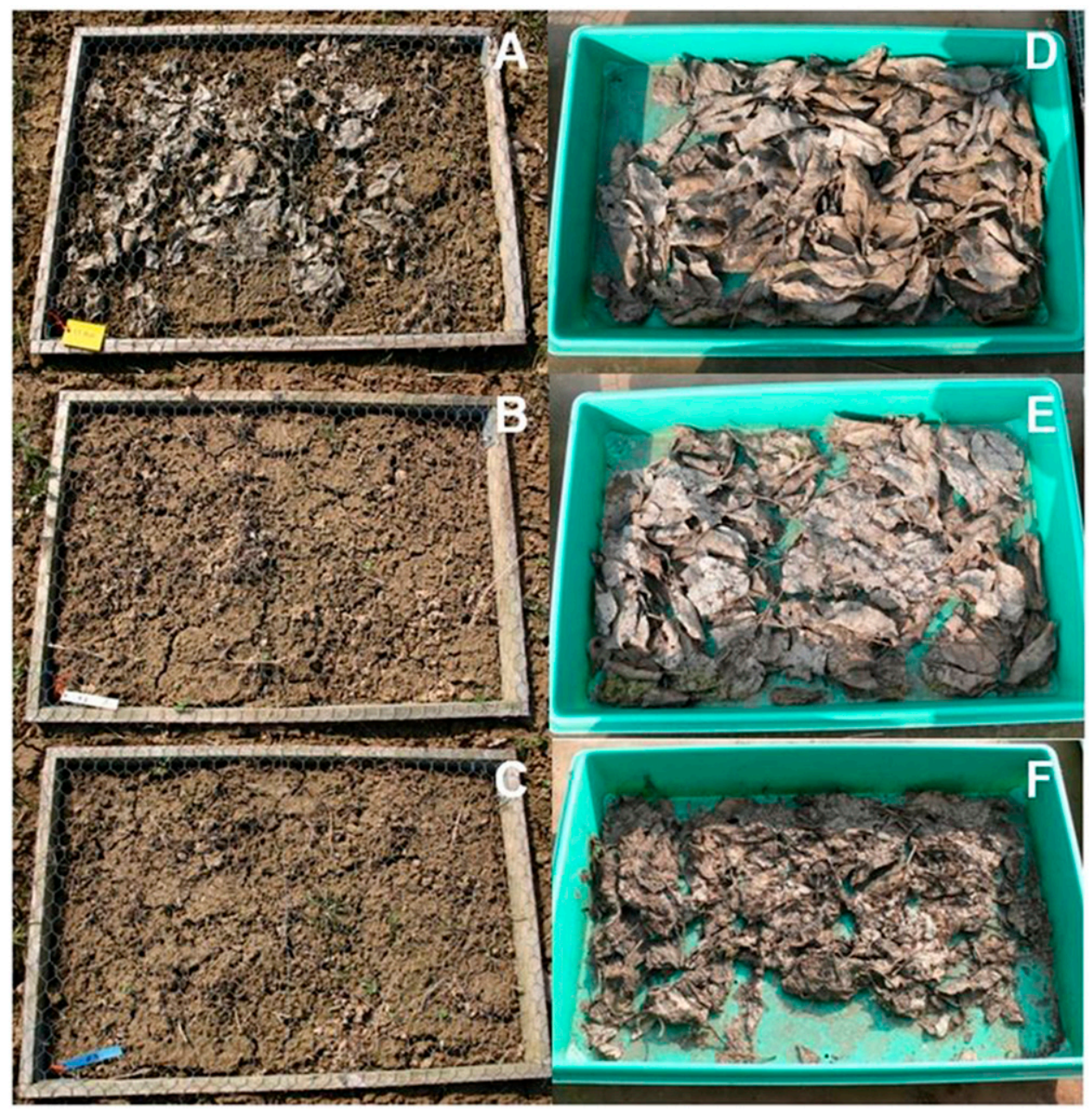

Fig. 3. Comparison of leaf litter decay in trays of apple scab-infected leaf litter on 27 March 2013. Leaves were placed in the orchard on 5 November 2012 and treated with the various nutrient solutions on 21 November 2012, 19 December 2012, 15 January 2013, and 13 February 2013. The left column shows the leaf decay due to earthworm activity for A, untreated leaves; B, yeast extract $6 \%$ (YE06)-treated leaves; and C, yeast extract 60\% (YE60)-treated leaves, which were spread directly onto the soil. The right column shows the leaf decay in plastic trays of $\mathbf{D}$, untreated leaves; $\mathbf{E}$, leaves treated with YE06; and $\mathbf{F}$, leaves treated with YE60. 
treatment. The first symptoms of leaf decomposition were visible from the end of January until the end of February. Four applications of 30 and $60 \%$ yeast extract resulted in the greatest symptoms of leaf degradation.

Burchill et al. (1965) demonstrated that the application of 5\% urea stimulates bacterial growth on the surface of the leaf. This resulted in an increase in microbial competition and subsequent leaf litter decay. It is possible that the yeast extract used in our study had a similar mode of action, potentially due to the high nitrogen content (9\%), which accelerated leaf degradation. The increased growth of microorganisms may have resulted in stronger competition for nutrients and space between $V$. inaequalis and other microorganisms, and some of them may act as antagonists via mycoparasitism (Benyagoub et al. 1998) or antibiosis (Heye and Andrews 1983; Hossain et al. 2009). We suspect that the growth of bipolar + and - mycelia of $V$. inaequalis, which occurs 2 to 3 weeks after leaf fall (Li and Xu 2002; MacHardy 1996), may have been disturbed. This could have disrupted the initiation and development of fruiting bodies.

The burrowing activity of earthworms and leaf decomposition rate were affected by the application of nutrient media. Between 2012 and 2014, the application of media containing degraded casein and $6 \%$ yeast extract was associated with increased leaf degradation due to earthworm activity (Fig. 4). In 2013 and 2014, the 30 and $60 \%$ yeast extract treatments were so efficient that all of the leaves were incorporated into the soil before ascospore maturation. Therefore, the ascospore potential could be almost completely eliminated. These findings are consistent with a previous study from Kollar and Pfeiffer (2005), who observed higher burrowing activity and decomposition rates when leaf litter was treated with yeast extract. Increased leaf burial was observed from a decrease in the amount of leaf litter compared with the untreated control group, in addition to an increase in sites where earthworms pulled the leaves into their burrows. The authors assumed that the preference was related to the ingredients of the nutrient media (specifically, the carbohydrates and amino acids). The increased earthworm activity observed in plots treated with yeast extract may be associated with increased leaf litter decay. It is well documented that freshly fallen apple leaves are unpalatable to earthworms but that they become acceptable after a short period of weathering and microbial degradation of distasteful substances such as phenolic compounds (Satchell 1967; Wright 1972). The particle size is also known to strongly influence the activity of earthworms, presumably because finer materials are more easily ingested and digested than coarser materials (Curry and Schmidt 2007). In our study, the treated leaves were more fragile and softer than the untreated leaf litter. We suggest that the enhanced leaf decay contributed to the increased burrowing activity of earthworms.

The present study has demonstrated that spraying leaf litter with yeast extract almost completely inhibits primary ascospore inoculum in orchards in different locations (LVWO and JKI). The experimental orchards were located a distance of $60 \mathrm{~km}$ apart, which suggests that the application of yeast extract may also be effective in other apple orchards located in the temperate zone, characterized by cool and moist weather in spring.

The reduction of ascospore discharge may allow growers to reduce the use of fungicides by delaying the onset of fungicide programs in early spring (MacHardy 1996; MacHardy et al. 1993). Gadoury et al. (1989) demonstrated that it is possible to delay the first fungicide application about 20 days by reducing the number of overwintering pseudothecia. In addition, the performance of fungicides with low efficacy such as elemental sulfur (Holb et al. 2003) or decreasing effectiveness (resistance development) such as dodine, benomyl, or DMI fungicides (Carisse and Dewdney, 2002) may be improved because of the lower inoculum.

The total abandonment of fungicide applications in spring would be counterproductive, because these will be necessary for the foreseeable future in order to prevent the development of resistance, control other fungal infections (e.g., Podosphaera leucotricha), and reduce infections caused by overwintering conidia or ascosporic inoculum from neighboring orchards.
Using a yeast extract presents several advantages, including the recycling of a byproduct of the brewery industry. During the manufacturing process, degenerated yeasts cells from the breweries were heated for a short time. These autolysis products were extracted, separated from cell walls, and spray dried. The yeast extract is certified as an ecological product in the EU (EG 834/2007 and EG 889/2008) and made from organic yeast cells. No GM technology is used in the production process. Therefore, yeast extracts should be certifiable for use in organic farming. This is important, because there are currently no chemicals labeled that can effectively reduce the overwintered inoculum in organic fruit production and only a few are labeled for integrated fruit production (e.g., urea).

The standard method of leaf litter shredding reduced the ascospore amount only around $85 \%$ and, often, not all of the leaves can be shredded because of the limited offset of the flail mower and the tree canopy (Sutton et al. 2000; Vincent et al. 2004). Standard 5\% urea
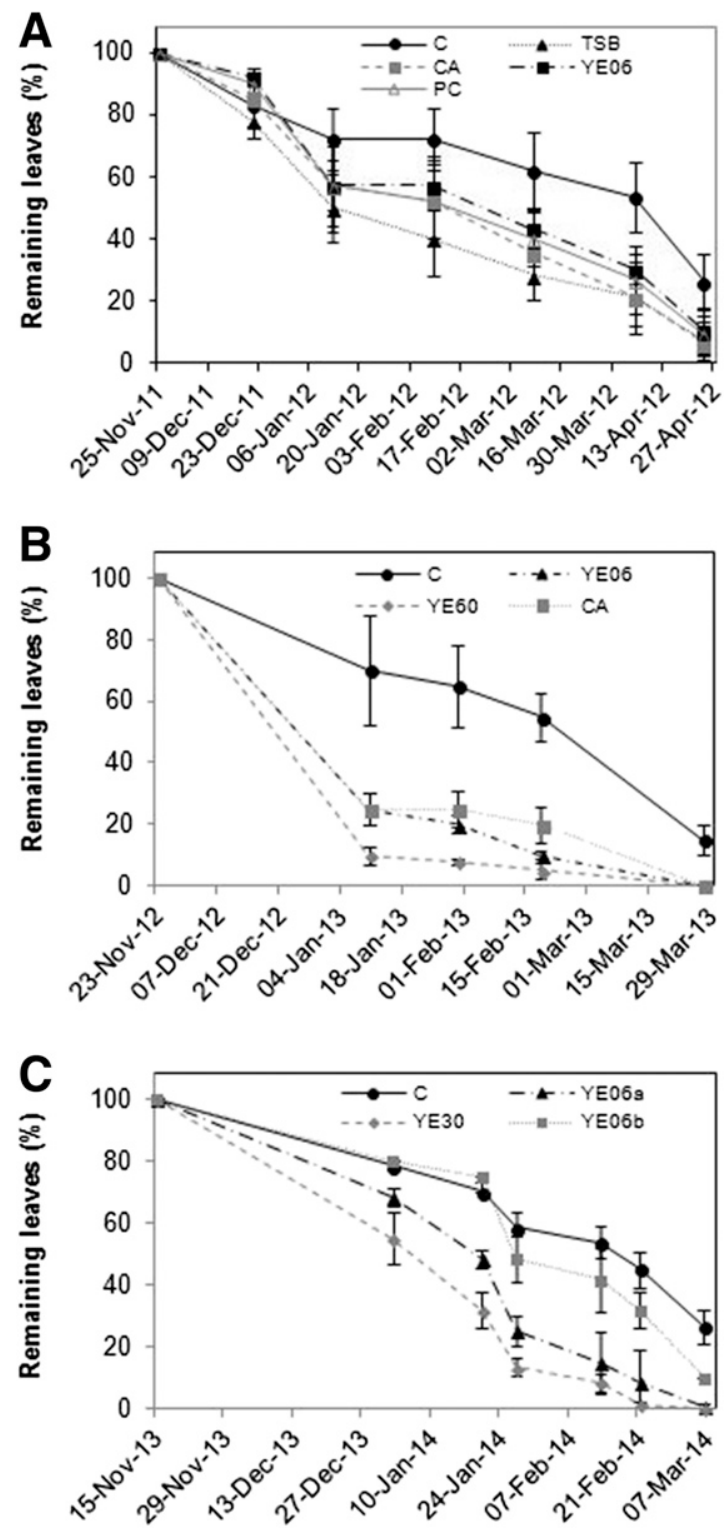

Fig. 4. Decomposition rate of leaf litter infected with Venturia inaequalis due to earthworm activity in A, 2011-12; B, 2012-13; and C, 2013-14. Treatment of leaf litter with casamino acids (CA), peptone casein (PC), tryptic soy broth (TSB), yeast extract $60 \%$ (YE60), yeast extract $30 \%$ (YE30), yeast extract $15 \%$ (YE15), yeast extract $6 \%$ (YE06), and untreated water control (C) were performed in 2011-12 on 25 November 2011, 16 January 2012, 5 March 2012, and 22 March 2012; in 2012-13 on 23 November 2012, 8 January 2013, and 13 February 2013; and in 2012-13 on 4 December 2013 and 9 January 2014. Leaf litter decay was investigated until the beginning of ascospore maturation on 27 April 2012, 31 March 2013, and 7 March 2014. Data are presented as the mean of three replicates \pm standard deviation. 
treatments reduced the ascospore amount nearly completely in this study. However, there were only slight indications of accelerated leaf litter decay compared with the untreated control. In contrast, the yeast extract reduced the ascospore inoculum significantly and promoted leaf removal by earthworms.

Shredding the leaf litter in autumn or in combination with urea treatments can reduce leaf scab incidence the following spring by 46 and $42 \%$ and fruit scab by 59 and 65\%, respectively (Sutton et al. 2000). Therefore, it can be assumed that yeast extract treatments should also reduce scab incidence, possibly to a greater extent because all leaves were eliminated until bud break. Further studies in different locations are required to investigate this hypothesis and demonstrate that the reduction of ascospore inoculum by yeast extract treatments can contribute to a reduction in disease incidence the following spring.

This new biological sanitation strategy could be established in areas of both integrated and organic apple production. In practice, the leaf litter treatments could be performed in combination with other orchard management activities after leaf fall (e.g., mulching and leaf shredding). The sanitation method may also reduce the inoculum of other diseases (e.g., Alternaria mali and Marssonina coronaria) and pests (e.g., leafminers) which overwinter in apple leaves on the orchard floor (Filajdic and Sutton 1995; Vincent et al. 2004).

\section{Acknowledgments}

This study was funded by the Federal Ministry of Food, Agriculture and Consumer Protection of Germany (project number 2809OE07). We thank S. Bermig, M. Reich, T. Mayer, A. Engelhard, V. Greulich, J. P. Petras, and K. Ehlert for technical support; and T. Ehlert for his assistance with English.

\section{Literature Cited}

Alt, S., and Kollar, A. 2010. Hydrodynamics of raindrop impact stimulate ascospore discharge of Venturia inaequalis. Fungal Biol. 114:320-324.

Benduhn, B., Zimmer, J., and Buchleither, S. 2014. Effect of mechanically removing of leaf litter on apple scab (Venturia inaequalis) infestation in organic apple production. Pages 40-44 in: Eco-Fruit: Proc. 17th Int. Conf. Organic Fruit Growing, Hohenheim, Germany. eds.

Benyagoub, M., Benhamou, N., and Carisse, O. 1998. Cytochemical investigation of the antagonistic interaction between a Microsphaeropsis sp. (isolate P130A) and Venturia inaequalis. Biochem. Cell Biol. 88:605-613.

Biggs, A. R., and Stensvand, A. 2014. Apple scab. Pages 8-11 in: Compendium of Apple and Pear Diseases and Pests, 2nd ed. T. B. Sutton, H. S. Aldwinckle, A. M. Agnello, and J. F. Walgenbach, eds. American Phytopathological Society, St. Paul, MN.

Bowen, J. K., Mesarich, C. H., Bus, V. G. M., Beresford, R. M., Plummer, K. M., and Templeton, M. D. 2011. Venturia inaequalis: The causal agent of apple scab. Mol. Plant Pathol. 12:105-122.

Burchill, R. T. 1968. Field and laboratory studies of the effect of urea on ascospore production of $V$. inaequalis (Cke.) Wint. Ann. Appl. Biol. 62:297-307.

Burchill, R. T., Hutton, K. E., Crosse, J. E., and Garrett, C. M. E. 1965. Inhibition of the perfect stage of Venturia inaequalis (Cooke) Wint. by urea. Nature 205:520-521.

Carisse, O., and Dewdney, M. 2002. A review of non-fungicidal approaches for the control of apple scab. Phytoprotection 83:1-29.

Chapman, K. S., Sundin, G. W., and Beckerman, J. L. 2011. Identification of resistance to multiple fungicides in field populations of Venturia inaequalis. Plant Dis. 95:921-926.

Cook, R. T. A. 1969. Studies on the overwintering of Venturia inaequalis (Cke.) Wint. Doctoral dissertation, University of London, United Kingdom.

Crosse, J. E., Garrett, C. M. E., and Burchill, R. T. 1968. Changes in microbial population of apple leaves associated with the inhibition of the perfect stage of Venturia inaequalis after urea treatment. Ann. Appl. Biol. 61:203-216.

Curry, J. P., and Schmidt, O. 2007. The feeding ecology of earthworms-A review. Pedobiologia (Jena) 50:463-477.

Filajdic, N., and Sutton, T. B. 1995. Overwintering of Alternaria mali, the causal agent of Alternaria blotch of apple. Plant Dis. 79:695-698.
Gadoury, D. M., MacHardy, W. E., and Rosenberger, D. M. 1989. Integration of pesticide application schedules for disease and insect pest control in apple orchards of the northeastern United States. Plant Dis. 73:98-105.

Helling, B., and Larink, O. 1998. Contribution of earthworm to nitrogen turnover in agricultural soils treated with different mineral N-fertilizers. Appl. Soil Ecol. 9:319-325.

Heye, C. C., and Andrews, J. H. 1983. Antagonism of Athelia bombacina and Chaetomium globosum to the apple scab pathogen Venturia inaequalis. Phytopathology 73:650-654.

Holb, I. J., de Jong, P. F., and Heijne, B. 2003. Efficacy and phytotoxicity of lime sulphur in organic apple production. Ann. Appl. Biol. 142:225-233.

Holb, I. J., Heijne, B., and Jeger, M. J. 2004. Overwintering of conidia of Venturia inaequalis and the contribution to early epidemics of apple scab. Plant Dis. 88: 751-757.

Hossain, M. B., Piotrowski, M., Lensing, J., and Gau, A. E. 2009. Inhibition of conidial growth of Venturia inaequalis by the extracellular protein fraction from the antagonistic bacterium Pseudomonas fluorescens Bk3. Biol. Control 48:133-139.

Keitt, G. W. 1936. Some problems and principles of orchard disease control with special reference to sanitation and related measures. J. Econ. Entomol. 29: 43-52.

Keitt, G. W., and Jones, L. K. 1926. Studies of the epidemiology and control of apple scab. Res. Bull. Wisc. Agric. Exp. Stn. 73. University of Wisconsin, Madison, WI.

Kollar, A. 1998. A simple method to forecast the ascospore discharge of Venturia inaequalis. J. Plant Dis. Prot. 105:489-495.

Kollar, A., and Pfeiffer, B. 2005. Schorfbekämpfung in der Zeit nach dem Blattfall? Obstbau 30:518-521.

Li, B., and Xu, C. 2002. Infection and development of apple scab (Venturia inaequalis) on old leaves. J. Phytopathol. 150:687-691.

Lowe, C. N., and Butt, K. R. 2003. Influence on food particle size on inter- and intra-specific interactions of Allobophora chlorotica (Savigny) and Lumbricus terrestris. Pedobiologia (Jena) 47:574-577.

MacHardy, W. E. 1996. Apple Scab: Biology, Epidemiology, and Management. American Phytopathology Society, Saint Paul, MN.

MacHardy, W. E., Gadoury, D. M., and Gessler, C. 2001. Parasitic and biological fitness of Venturia inaequalis: Relationship to disease management strategies. Plant Dis. 85:1036-1051.

MacHardy, W. E., Gadoury, D. M., and Rosenberger, D. A. 1993. Delaying the onset of fungicide programs for the control of apple scab in orchards with low potential of ascospore dose of Venturia inaequalis. Plant Dis. 77:372-375.

Mills, W. D. 1944. Efficient use of sulfur dusts and sprays during rain to control apple scab. N. Y. Agric. Exp. Stn. Ithaca Bull. 630.

Ross, R. G., and Hamlin, S. A. 1962. Production of perithecia of Venturia inaequalis (Cke.) Wint. on sterile apple leaf discs. Can. J. Bot. 40:629-635.

Rüdiger, F. M., Nietsch, N., Pfeiffer, B., and Kollar, A. 2012. Efficacy of alternative substances to control apple scab by leaf litter treatments. Pages 239-244 in: Eco-Fruit: Proc. 15th Int. Conf. Organic Fruit Growing, Hohenheim, Germany.

Satchell, J. E. 1967. Lumbricidae. Pages 259-322 in: Soil Biology. A. Burgess and F. Raw, eds. Academic Press, New York.

Satchell, J. E., and Loewe, D. G. 1967. Selection of leaf litter by Lumbricus terrestris. Pages 102-119 in: Progress in Soil Biology. O. Graff and J. E. Satchell, eds. North Holland Publishing Co., Amsterdam.

Schwabe, W. F. S. 1979. Changes in the scab susceptibility of apple leaves as influenced by age. Phytophylactica 11:53-56.

Schwabe, W. F. S., Jones, A. L., and Jonker, J. P. 1984. Changes in the susceptibility of developing apple fruit to Venturia inaequalis. Phytopathology 74:118-121.

Sutton, D. K., and MacHardy, W. E. 1993. The reduction of ascosporic inoculum of Venturia inaequalis by orchard sanitation. (Abstr.) Phytopathology 83:247.

Sutton, D. K., MacHardy, W. E., and Lord, W. G. 2000. Effect of shredding or treating apple leaves litter with urea on ascospore dose of Venturia inaequalis and disease buildup. Plant Dis. 84:1319-1326.

Vincent, C., Rancourt, B., and Carisse, O. 2004. Apple leaf shredding as a nonchemical tool to manage apple scab and spotted tentiform leafminer. Ecosyst. Environ. 104:595-604.

Wallace, E. 1913. Scab disease of apples. Cornell Univ. Agric. Exp. Stn. Bull. 335: 545-624.

Wright, M. A. 1972. Factors governing ingestion by the earthworm Lumbricus terrestris with special reference to apple leaves. Ann. Appl. Biol. 70:175-188. 